\title{
Low birth weight in patients with heart failure does birth weight differ among patient subgroups?
}

\author{
Gloria Bagadur'* , Ivo Planinc², Boško Skorić², Jana Ljubas Maček², Željko Baričević², \\ Vedran Velagićc ${ }^{2}$, Jure Samardžićc ${ }^{2}$, Hrvoje Jurin², Maja Cikeš ${ }^{2}$, Davor Miličićc ${ }^{2}$ \\ ${ }^{1}$ University of Zagreb School of Medicine, Zagreb, Croatia \\ ${ }^{2}$ University of Zagreb School of Medicine, University Hospital Centre Zagreb, Zagreb, Croatia
}

\begin{abstract}
Objectives: Low birth weight (LBW) occurs in $5-10 \%$ of the general population. Several studies link cardiovascular diseases in adulthood to LBW ${ }^{1,2}$. Furthermore, LBW and failure to thrive in early life were shown to be associated with systemic low-grade inflammation in adult age which was suggested as one of the potential risk factors for the development of coronary heart disease ${ }^{3}$. However, little is known about the relation of dilated cardiomyopathy (DCM) and other causes of heart failure (HF) to LBW. Thus, we aimed to study the occurrence of LBW in our centre's HF population as well as to compare birth weights (BW) between patient subgroups based on underlying forms of cardiomyopathies.
\end{abstract}

Patients and Methods: From 2012 to 2013, 161 adult pts with a history of HF were admitted to our HF centre. From that number, we studied 67 pts with known birth weight (BW). From this number of patients, 32 had idiopathic dilated cardiomyopathy (iDCM), 19 pts had ischemic cardiomyopathy (ICM), 10 pts had history of myocarditis 4 , were diagnosed with arrhythmogenic right ventricular dysplasia (ARVD) and 2 with hypertrophic cardiomyopathy (HCM). We compared reported BW between these subgroups with a cut-off for LBW set at 2,500 $\mathrm{g}$ according to the WHO definition. The values are given as mean value \pm standard deviation. The Student's t-test was used to test statistical significance. A P value $<0.05$ was deemed statistically significant.

Results: Overall, $10.4 \%$ of the 67 studied HF patients had LBW. More specifically, LBW was present in 2/10 (20\%) pts with history of myocarditis, 4/32 (12.5\%) pts with iDCM, 1/19 $(5 \%)$ pts with ICM and none of the patients with $\mathrm{HCM}$ or ARVD. Average BW was notably lower in pts with history of

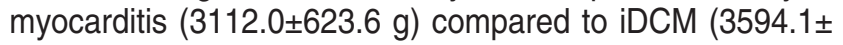
$889.1 \mathrm{~g}, \mathrm{P}=0.03)$ and ICM $(3652.6 \pm 839.7 \mathrm{~g}, \mathrm{P}=0.03)(\mathrm{Fi}-$ gure 1).

Conclusion: This study demonstrates a higher occurrence of LBW in certain subgroups of our centre's HF population than the occurrence of LBW in the general population. Namely, the incidence of LBW was the highest in the subgroup of pts with a history of myocarditis and this subpopulation had a significantly lower mean BW than patients with iDCM or ICM. These results suggest that LBW is a potential risk factor for the development of HF. Our study warrants further investigation into the inflammatory mechanisms, potentially linking LBW to the development of various forms of cardiomyopathies, particularly the susceptibility to myocarditis.

KEYWORDS: heart failure, dilated cardiomyopathy, ischaemic cardiomyopathy, myocarditis, low birth weight.

CITATION: Cardiol Croat. 2013;8(9):293.

\section{Received: $30^{\text {th }}$ Jul 2013}

*Address for correspondence: Medicinski fakultet Sveučilišta u Zagrebu, Šalata 3, HR-10000 Zagreb, Croatia.

Phone: +385-97-7818-746

E-mail: igloria.lyl@ hotmail.com

Figure 1. The relation between birth weights among the studied groups of patients.

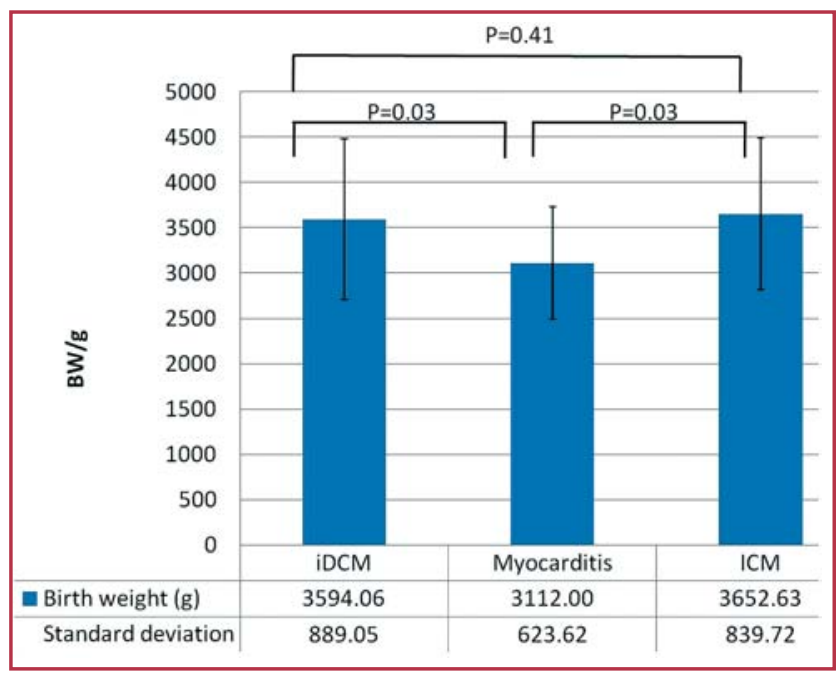

$\mathrm{BW} / \mathrm{g}=$ birth weight/grams, $\mathrm{IDCM}=$ idiopathic dilated cardiomyopathy, ICM=ischemic cardiomyopathy

\section{Literature}

1. Crispi F, Bijnens B, Figueras F, et al. Fetal growth restriction results in remodeled and less efficient hearts in children. Circulation. 2010;121:2427-36.

2. Kaijser M, Edstedt Bonamy AK, Akre O, et al. Perinatal risk factors for ischemic heart disease: disentangling the roles of birth weight and preterm birth. Circulation. 2008;117:40510.

3. Canoy D, Pouta A, Ruokonen A, et al. Weight at birth and infancy in relation to adult leukocyte count: a population-based study of 5619 men and women followed from the fetal period to adulthood. J Clin Endocrinol Metab. 2009;94:1916-22. 